\title{
Appropriation is the mother of invention
}

\author{
Jonathan M. Chen, MD
}

From the Department of Congenital Cardiac Surgery, Seattle Children's Hospital, Seattle, Wash

Disclosures: Author has nothing to disclose with regard to commercial support.

Received for publication March 22, 2018; accepted for publication March 23, 2018; available ahead of print April $18,2018$.

Address for reprints: Jonathan M. Chen, MD, Department of Congenital Cardiac Surgery, Seattle Children's Hospital, 4800 Sand Point Way, NE, RC2.820, Seattle, WA 98105 (E-mail: jmchen@uw.edu).

J Thorac Cardiovasc Surg 2018;156:330-1

$0022-5223 / \$ 36.00$

Copyright (c) 2018 by The American Association for Thoracic Surgery

https://doi.org/10.1016/j.jtcvs.2018.03.091

Keith Reemtsma was legendary for reminding junior faculty that "every good idea you have was previously described by the Germans in the 19th century" (K. Reemtsma, personal communication). Although he meant this (as he intended many such aphorisms) to be amusingly provocative, he also promoted the notion that simply because ideas or operations had been discarded (or infrequently applied), did not necessarily mean that they could not have innovative new applications. In congenital cardiac surgery, most recently this has been exemplified by the renaissance of the Potts shunt for use "in reverse" in patients with pulmonary hypertension. ${ }^{1}$ In this issue of the Journal, Paul and colleagues ${ }^{2}$ describe a novel application of a hepatic vein-to-systemic vein shunt to address hepatic venous congestion and portal hypertension in a teenager with heterotaxy.

The increasing appreciation of the salutary effects of hepatic factor in suppressing the development of pulmonary arteriovenous malformations has provided renewed interest in surgical techniques that can help to provide more balanced quantities of the hepatic elixir to bilateral lung fields in patients with a single ventricle. In particular, for those single-ventricle patients with heterotaxy syndrome and anomalous systemic venous return (eg, interrupted inferior vena cava), there has been recent interest in pursuing hepatic vein-to-(hemi)azygous vein shunts to provide hepatic factor to the lungs via an ultimate Kawashima cavopulmonary connection. ${ }^{3,4}$

In the case described by Paul and colleagues, ${ }^{2}$ the clinical challenge was how to afford decompression of an obstructed left-sided hepatic venous confluence into the systemic circulation when anatomic barriers such as atrial situs, hepatic varicies, and atrioventricular valves preclude the creation of an unimpeded baffle or simple off-pump interposition graft. ${ }^{4}$ Borrowing in part from the techniques of hepatic-toazygous vein shunts as well as those of extracardiac Fontan conduits, the authors successfully used a ringed

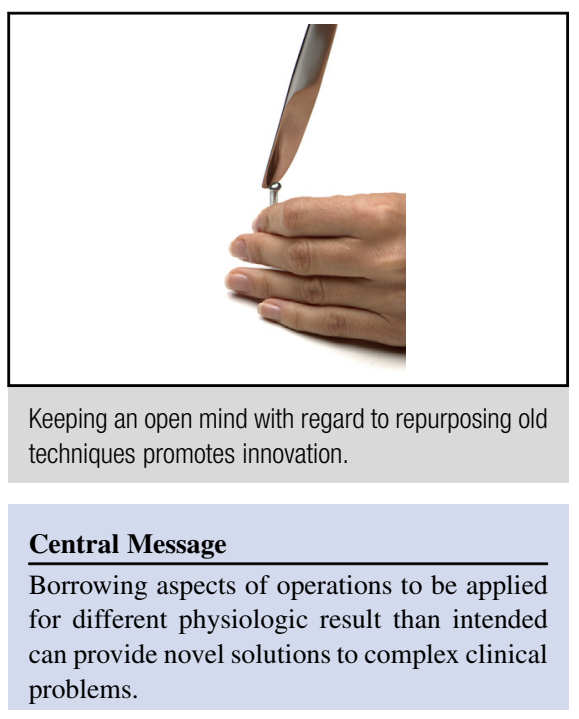

See Article page 327.

polytetrafluoroethylene tube graft to unload the hepatic afterload into the innominate vein with excellent clinical result.

Although the authors maintain that a hepatic-to-azygous vein interposition graft would have been fraught with complications due to varices, one can imagine an aggressive interventionalist suggesting that the patient consider a different kind of appropriation: One that takes the percutaneous bravado of a transhepatic portocaval shunt (eg, TIPS procedure) and creates a hepatic vein to azygous vein connection, in essence an intrahepatic systemic to systemic bypass. Whatever the connection, all venous drainage must ultimately lead to Rome (without obstruction), and the successful normalization of the patient's hepatic chemistries proves this concept.

Necessity, undeniably, is the mother of invention, but sometimes it is borne by new life hacks-a knife as a screwdriver or a lighter as a bottle opener-simple, clever, and often transformative. Keeping an open mind with regard to repurposing old paradigms not infrequently promotes innovation.

\section{References}

1. Blanc J, Vouhé P, Bonnet D. Potts shunt in patients with pulmonary hypertension. N Engl J Med. 2004;350:623.

2. Paul E, Torres AJ, Chelliah A, Martinez M, Ferris AM, Kalfa DM. Extra-anatomic suprahepatic to innominate vein conduit in heterotaxy. J Thorac Cardiovasc Surg. 2018; $156: 327-9$

3. McElhinney DB, Marx GR, Marshall AC, Mayer JE, del Nido PJ. Cavopulmonary pathway modification in patients with heterotaxy and newly 
diagnosed or persistent pulmonary arteriovenous malformations after a modified Fontan operation. J Thorac Cardiovasc Surg. 2011;141: 1362-70.

4. Arrigoni SC, van den Heuvel F, Willems TP, Hillege H, Lindberg HL, Berger RMF, et al. Off-pump hepatic to azygos connection via thoracotomy for re- lief of fistulas after a Kawashima procedure: ten year results. J Thorac Cardiovasc Surg. 2015; 149:1524-30.

5. Wu I-H, Nguyen KH. Redirection of hepatic drainage for treatment of pulmonary arteriovenous malformations following the Fontan procedure. Pediatr Cardiol. 2006;27:519-22. 